\title{
Evaluation of the Risk of Falls in the Patients Hospitalized in A Urology Inpatient Clinic
}

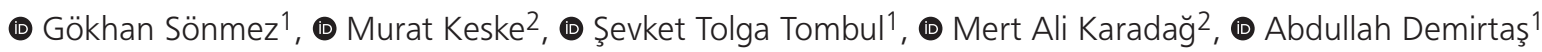 \\ ${ }^{1}$ Erciyes University Faculty of Medicine, Department of Urology, Kayseri, Turkey \\ 2 University of Health Sciences, Kayseri City Hospital, Clinic of Urology, Kayseri, Turkey
}

\begin{abstract}
Objective: Falls are a significant cause of morbidity and mortality, particularly in hospitalized patients. In this study, we aimed to evaluate the risk of falls in the patients hospitalized in a urology clinic.

Materials and Methods: The study included patients that were hospitalized in a urology clinic between November and December 2018. All the patients were administered both Itaki Fall Risk scale (IFS) and Morse Fall scale (MFS). Demographic and clinical characteristics, history of falls within the past six months, type of surgery, primary diagnosis (urooncological vs non-urooncological), and the department/unit from which the patients were referred [outpatient clinic vs emergency service/intensive care unit (ICU)] were recorded.

Results: The risk of falls was significantly higher in the patients with urooncological diseases compared to the patients with non-urooncological diseases $(p<0.001)$ and in the patients referred from emergency service/ICU compared to the patients referred from outpatient clinics $(p<0.001)$. Moreover, the patients with a history of falls within the past six months were found to be at higher risk of falls compared to the patients with no history of falls both on IFS and MFS ( $p=0.002, p=0.01$, respectively).

Conclusion: Hospitalized patients should be closely followed due to the risk of falls, particularly the cancer patients and the patients referred from the emergency service or ICU.
\end{abstract}

Keywords: Fall, urology, risk

\section{Introduction}

A fall is defined by the World Health Organization as an event that results in a person coming to rest inadvertently on the ground or floor or other lower level, mostly due to the carelessness of the person or an accident (1). Falls are a significant cause of morbidity and mortality, particularly in oldage patients (aged 65 years or older). About one-third of these individuals experience falls each year, with $10-20 \%$ of the falls resulting in severe injury (2). However, young individuals also have a risk of falls, and it has been shown that about $16 \%$ of young adults experience fall injuries due to various reasons (3). In hospitalized patients, on the other hand, falls can result in injuries and loss of functions, thereby leading to prolonged hospital stays, increased treatment costs, and reduced quality of life. Moreover, these falls may also result in the development of anxiety and fear both in the patients and the healthcare staff (4). In previous studies, the rates of falls in hospitalized patients have been reported to range between 2.9-13 falls per 1,000 bed days (5).

Common urological factors associated with increased risk of falls include overactive bladder, nocturia associated with benign prostatic hyperplasia, lower urinary symptoms (such as pollakiuria), urological malignancies, and alpha-blocker therapy $(3,6,7,8,9,10)$. Additionally, the risk of falls is increased in patients undergoing urological surgeries and, in the patients, hospitalized in the urology clinic, as in other types of surgeries and other clinics. On the other hand, in patients undergoing surgery, some other factors can also increase the risk of postoperative falls, such as patient-related causes, duration of surgery, anesthetic management, changes in fluid-electrolyte balance, and blood flow, and pain (11). 
The aim of this prospective study was to evaluate the risk of falls and to determine the groups with a high risk of falls in patients hospitalized in a urology inpatient clinic.

\section{Materials and Methods}

\section{Patient Selection and Study Design}

The study included patients that were hospitalized in Kayseri City Hospital Urology Department Inpatient Clinic between November and December 2018. Patients with a malignancy other than urological malignancies and patients aged less than 18 years were excluded from the study. The patients were administered both Itaki Fall Risk scale (IFS) and Morse Fall scale (MFS). Moreover, each patient was queried as to whether they had experienced any falls within the past six months. Age, body mass index, types of surgery, and the reason for hospitalization (surgical treatment vs medical follow-up) were recorded for each patient. The surgical types were divided into six categories: (I) scrotal surgeries (varicocelectomy, hydrocelectomy, orchiectomy), (II) transurethral resection of bladder tumor (TURBT), (III) transurethral resection of the prostate, (IV) radical surgeries (radical cystectomy, radical/partial nephrectomy, radical prostatectomy), (V) urinary stone surgeries (ureterorenoscopy, percutaneous nephrolithotomy, cystolithotripsy), and (VI) other urological surgeries (urogynecological surgeries, reconstructive surgeries, trauma surgeries). The patients were divided into two groups as (a) patients hospitalized electively (i.e., referred from polyclinics) and (b) patients hospitalized under emergency conditions [i.e., referred from emergency service or an intensive care unit (ICU))]. Additionally, the patients were divided into two groups based on their diagnoses: (i) urooncological (UO) and (ii) non-urooncological (NUO). The total length of hospital stay was recorded for each patient. The risks of falling were determined and compared among the groups based on the IFS and MFS scores.

Itaki Fall Risk Scale (IFS): This scale was introduced by the Republic of Turkey Ministry of Health Performance Management and Quality Improvement Directory in 2011. The scale consists of 19 items regarding the main risk factors related to falls in patients, including 11 minor and nine major risk factors. Each minor factor is scored as 1 point and each major factor is scored as 5 points. Based on the total score, the patients are categorized as being at low or high risk of falls, with a score of $<5$ indicating low risk and a score of $>5$ indicating a high risk. Accordingly, higher scores demonstrate a higher risk of falls (12).

Morse Fall Scale (MFS): This scale was first introduced in 1985 and consisted of six subscales: a history of falling, secondary diagnosis, ambulatory aid, IV/heparin lock, gait/transferring, and mental status. Based on the total score obtained on MFS, the patients are determined to be at low, moderate, or high risk of falls. The scale was revised in 2009 (13).

\section{Ethical Approval}

The study was approved by the Ministry of Health, Kayseri City Hospital Medical Specialty Committee and the Erciyes University Faculty of Medicine Ethics Committee (approval no: 2018/531).

\section{Statistical Analysis}

Data were analyzed using SPSS for Windows version 22.0 (IBM Corp., Armonk, NY, USA). Normality tests were performed using a Shapiro-Wilk test and histograms. Continuous variables with normal distribution were expressed as mean \pm standard deviation. Continuous variables with non-normal distribution were expressed as median $\left(25^{\text {th }}-75^{\text {th }}\right.$ percentiles) and were compared using the Mann-Whitney $U$ test. Categorical variables were compared using the chi-square test. A $p$ value of $<0.05$ was considered significant.

\section{Results}

The study included a total of 368 patients. The demographic and clinical characteristics of the patients are presented in Table 1. The most common surgical procedures performed in the patients were urinary stone surgeries (27.7\%). Of the 368 patients, $126(34.2 \%)$ of them had UO, and 242 (65.8\%) had NUO diseases. For each patient, four parameters included Itaki score (Is), Itaki risk level (Ir), Morse score (Ms), and Morse risk level (Mr) were determined, which indicated that the UO group had a significantly higher risk of falls compared to the NUO group. In order to decrease the effect of "age" on fall risk and to obtain a more homogenous age group, patients between the ages of 41-65, who could be defined as middle age group, were evaluated for fall risk. Similarly, the risk of falling was significantly

\begin{tabular}{|c|c|}
\hline Parameter & $\begin{array}{l}\text { Mean } \\
\text { (range or percentile) }\end{array}$ \\
\hline Age (years) & $62.00(36.00-69.75)$ \\
\hline \multicolumn{2}{|l|}{ Gender (n, \%) } \\
\hline Female & $48(13 \%)$ \\
\hline Male & $320(87 \%)$ \\
\hline Body mass index $\left(\mathrm{kg} / \mathrm{m}^{2}\right)$ & $24.1(22.3-26.5)$ \\
\hline \multicolumn{2}{|l|}{ Primary diagnosis (n, \%) } \\
\hline Urooncological & $126(34.2 \%)$ \\
\hline Non-urooncological & $242(65.8 \%)$ \\
\hline \multicolumn{2}{|l|}{ Department/Unit of referral $(n, \%)$} \\
\hline Polyclinic & $301(82 \%)$ \\
\hline Emergency & $47(13 \%)$ \\
\hline ICU & $20(5 \%)$ \\
\hline Hospital stay (days) & $2.0(2.0-3.0)$ \\
\hline \multicolumn{2}{|l|}{ Surgical procedure $(n, \%)$} \\
\hline Urinary stone surgery & $102(27.7 \%)$ \\
\hline Transurethral resection of bladder tumor & $97(26.4 \%)$ \\
\hline Scrotal surgery & $60(16.3 \%)$ \\
\hline Transurethral resection of the prostate & $59(16 \%)$ \\
\hline Radical surgeries & $22(6 \%)$ \\
\hline Others & $16(4.3 \%)$ \\
\hline Medical follow-up & $12(3.3 \%)$ \\
\hline
\end{tabular}


higher in the UO group when the patients aged 41-65 years were examined (Table 2). Eleven percent of all patients (41 out of 368) had a history of at least one fall in the past one year, which was significantly higher in the UO group (17\%; 21 out of 126) compared to the NUO group (8\%; 20 out of 242) $(\mathrm{p}=0.015)$. Moreover, the Is, Ir, Ms, and Mr results indicated that the risk of falls was significantly higher in the patients with a history of at least one fall compared to the patients with no history of falls (Table 3). Of the 368 patients, 301 (82\%) of them were hospitalized electively, and 67 (18\%) were hospitalized under emergency conditions (emergency service or ICU), and the risk of falls was significantly higher in the patients hospitalized electively compared to the patients hospitalized under emergency conditions (Table 4). However, no significant difference was found between emergency service and ICU groups with regard to the Is, Ir, Ms, and Mr results ( $p=0.069$, $p=0.251, p=0.409, p=0110$, respectively). No fall occurred in any patient in the Urology inpatient clinic throughout the study period.

\section{Discussion}

The most important finding of this study was that the risk of falls was lower in the patients hospitalized electively compared to those hospitalized under emergency conditions. Another important finding was that the patients with urological malignancies had a significantly higher risk of falls and a significantly higher incidence of a history of falls compared to patients without urological malignancies.

Urolithiasis is a highly prevalent health problem encountered in Europe and Turkey $(14,15)$, with a reported prevalence of $15 \%$ in Turkey (15). As consistent with the literature, urinary stone surgeries were the most common surgeries performed in our clinic throughout the study period (27.7\%). Bladder cancer is a common urological malignancy, and its treatment requires repeat cystoscopy and TURBT, particularly at the early stages of the tumor (16). In our study, TURBT was the second most common surgical procedure performed in our patients.

Of the 368 patients in our study, the frequency of a history of falls within the past six months was significantly higher

\begin{tabular}{|c|c|c|c|}
\hline \multirow[b]{3}{*}{ Parameter } & \multirow{2}{*}{\multicolumn{3}{|c|}{ History of falls within the past six months }} \\
\hline & & & \\
\hline & $\begin{array}{l}\text { Yes } \\
(n=41)\end{array}$ & $\begin{array}{l}\text { No } \\
(n=347)\end{array}$ & p \\
\hline Age (years) & $67.0(54.0-77.0)$ & $61.0(36.0-69.0)$ & 0.007 \\
\hline Itaki score & $7.0(1.0-9.5)$ & $2.0(0.0-8.0)$ & 0.004 \\
\hline MFS score & $25.0(5.0-50.0)$ & $15.0(0.0-25.0)$ & 0.002 \\
\hline \multicolumn{3}{|l|}{ Itaki level } & \multirow{3}{*}{0.010} \\
\hline Low risk & $36.6 \%$ & $57.8 \%$ & \\
\hline High risk & $63.4 \%$ & $42.2 \%$ & \\
\hline \multicolumn{3}{|l|}{ MFS level } & \multirow{4}{*}{0.002} \\
\hline Low risk & $41.5 \%$ & $66.7 \%$ & \\
\hline Moderate risk & $39.0 \%$ & $26.0 \%$ & \\
\hline High risk & $19.5 \%$ & $7.3 \%$ & \\
\hline
\end{tabular}

\begin{tabular}{|c|c|c|c|}
\hline \multirow[b]{2}{*}{ Parameter } & \multicolumn{3}{|c|}{ Department/Unit of referral } \\
\hline & $\begin{array}{l}\text { Polyclinic } \\
(n=301)\end{array}$ & $\begin{array}{l}\text { Emergency service/ICU } \\
(n=67)\end{array}$ & p \\
\hline Age (years) & $55.0(33.0-68.0)$ & $78.0(68.0-81.0)$ & $<0.001$ \\
\hline Itaki score & $1.0(0.0-6.0)$ & $9.0(8.0-10.0)$ & $<0.001$ \\
\hline MFS score & $0.0(0.0-25.0)$ & $50.0(25.0-75.0)$ & $<0.001$ \\
\hline \multicolumn{3}{|l|}{ Itaki level } & \multirow{3}{*}{$<0.001$} \\
\hline Low risk & $66.8 \%$ & $4.5 \%$ & \\
\hline High risk & $33.2 \%$ & $95.5 \%$ & \\
\hline \multicolumn{3}{|l|}{ MFS level } & \multirow{4}{*}{$<0.001$} \\
\hline Low risk & $74.8 \%$ & $14.9 \%$ & \\
\hline Moderate risk & $21.3 \%$ & $55.2 \%$ & \\
\hline High risk & $4.0 \%$ & $29.9 \%$ & \\
\hline
\end{tabular}

\begin{tabular}{|c|c|c|c|c|c|c|}
\hline Parameter & \multicolumn{3}{|l|}{$\begin{array}{l}\text { Primary diagnosis } \\
\text { (for all patients) }\end{array}$} & \multicolumn{3}{|c|}{$\begin{array}{l}\text { Primary diagnosis } \\
\text { (for 41-65 years old) }\end{array}$} \\
\hline Age (years) & $69.00(62.00-79.00)$ & $44.00(30.75-66.00)$ & $<0.001$ & $58.50(55.00-62.00)$ & $60.00(47.50-62.00)$ & 0.122 \\
\hline Itaki score & $8.0(5.0-9.0)$ & $1.0(0.0-3.0)$ & $<0.001$ & $5.0(5.0-7.0)$ & $1.0(0.8-2.0)$ & $<0.001$ \\
\hline MFS score & $25.0(15.0-50.0)$ & $0.0(0.0-15.0)$ & $<0.001$ & $15.0(15.0-25.0)$ & $0.0(0.0-15.0)$ & $<0.001$ \\
\hline Low risk & $8.7 \%$ & $79.8 \%$ & \multirow{2}{*}{$<0.001$} & $15.6 \%$ & $83.7 \%$ & \multirow{2}{*}{$<0.001$} \\
\hline High risk & $91.3 \%$ & $20.2 \%$ & & $84.4 \%$ & $16.3 \%$ & \\
\hline \multicolumn{3}{|l|}{ MFS level } & \multirow{3}{*}{$<0.001$} & & & \multirow{3}{*}{0.001} \\
\hline Low risk & $29.4 \%$ & $81.8 \%$ & & $59.4 \%$ & $89.4 \%$ & \\
\hline Moderate risk & $49.2 \%$ & $16.1 \%$ & & $40.6 \%$ & $10.6 \%$ & \\
\hline
\end{tabular}


in the UO group compared to the NUO group (18\% vs $8 \%$ ) $(p=0.015)$. Moreover, the Is, Ir, Ms, and $\mathrm{Mr}$ results were significantly higher in the UO group compared to the NUO group $(p<0.001)$. However, as expected, cancer patients were older than NUO patients, and a homogeneous group of age could not be obtained. In order to decrease the effect of "age" on fall risk and to obtain a more homogenous age group, patients between the ages of 41-65, who could be defined as middle age group, were evaluated for fall risk. Similarly, UO patients between 41-65 years of age were found to have a higher risk of falling. According to these results, it can be said that cancer increases the risk of falling regardless of the age effect. A recent retrospective study evaluated a cohort of 304 cancer patients with urological, hematological, breast, lung, and gynecological cancers over a follow-up period of 6 months and reported that $35.8 \%$ of the patients had a history of at least one fall. The study concluded that old age and cancer patients have a significantly higher risk of falls compared to the general population (9). However, unlike our study, that study evaluated patients aged 65 years or older as well. In a more recent study, Wildes et al. (17) evaluated a cohort of 498 cancer patients aged 65 years or older and reported that $18.2 \%$ of the patients had a history of at least one fall within the past six months. Similarly, another study that was conducted in 2017 evaluated 280 patients with prostate cancer and revealed that $28 \%$ of the patients had a history of at least one fall within the past one year (18). However, this high rate of falls could have been related to the fact that the study had a longer study period compared to that of our study. On the other hand, two recent systematic reviews suggested that cancer patients have a significantly higher risk of falls compared to the general population $(19,20)$. Taken together, all these findings implicate that the findings of our study are consistent with those reported in the literature.

In our study, the risk of falls was lower in the patients hospitalized electively compared to those hospitalized under emergency conditions. In a study conducted in 2016, Demir et al. (21) reported that $66.6 \%$ of the patients hospitalized in the internal disease's ICU had a relatively higher risk of falls. Çinarli et al. (22) reported that the risk of falls was higher, particularly in the patients aged 75 years or older, patients with chronic diseases, and patients with a history of falls. Several factors are directly associated with an increased risk of falls, including muscle weakness, behavioral disturbance, agitation, or confusion, and postural hypotension or syncope $(23,24)$. Accordingly, our finding that indicated that the patients hospitalized under emergency conditions had a significantly higher risk of falls compared to those hospitalized electively could be explained by these factors.

Urbanetto et al. (25) analyzed the risk prediction capability and validity of the Brazilian version of MFS and found that MFS can appropriately predict the risk of falls. Similarly, in a Korean study, Baek et al. (26) evaluated the validity of MFS in 151 patients with a history of falls and 694 patients with no history of falls and revealed a sensitivity of 0.72 and a specificity of 0.91 for MFS. In our study, we evaluated the risk of falls over six months, and we found that among the patients with a history of falls, the proportions of the patients classified as being at moderate and high risk of falls on MFS were higher than those classified as being at low risk (Table 3). Additionally, although similar outcomes were obtained on the IFS, which is a national scale administered in Turkey, the outcomes of this scale could not be used for obtaining definitive evaluations since there are no international studies validating the reliability of this scale.

\section{Study Limitations}

The primary limitation of our study was that it only evaluated the history and risk of falls but did not include a long-term, prospective analysis of the falls. Furthermore, the fact that the patients in the UO group and the patients hospitalized under emergency conditions were significantly older than the other patients led to controversial findings. Old-age patients are typically expected to have an increased risk and frequency of falls; however, aging and cancer development cannot be distinguished from each other. In order to minimize this effect, a homogeneous group consisting of only patients aged 41-65 years was formed, but the small patient number of these groups is a limitation of our study. Additionally, hospitalization of older patients in ICUs and emergency services is inevitable, and thus, the hospitalization of these patients is directly associated with aging. However, it remains controversial whether there is an association between the high risk of falls in such patients and the age or clinical characteristics of these patients. Meaningfully, the absence of such an analysis was another limitation of our study. Finally, despite the rapid patient circulation in urology inpatient clinics, our study had a relatively short duration of the study period and a relatively smaller patient population.

\section{Conclusions}

Patients hospitalized in inpatient clinics should be closely followed due to the risk of falls. In particular, utmost care should be taken for cancer patients and the patients referred from the emergency service or ICU. Further multi-center studies with larger patient series and longer follow-up periods are needed.

\section{Acknowledgements}

Publication: The results of the study were not published in full or in part in form of abstracts.

Contribution: There is not any other contributors who may not be listed as authors.

Conflict of Interest: No conflict of interest was declared by the authors.

Financial Disclosure: The authors declared that this study received no financial support.

\section{Ethics}

Ethics Committee Approval: The study was approved by the Ministry of Health Kayseri City Hospital Medical Specialty Committee and the Erciyes University Faculty of Medicine Ethics Committee (approval no: 2018/531).

Informed Consent: Retrospective study. 
Peer-review: Externally peer-reviewed.

\section{Authorship Contributions}

Concept: A.D., M.A.K., Design: A.D., M.A.K., Data Collection or Processing: Ş.T.T., Analysis or Interpretation: G.S., M.K., Literature Search: Ş.T.T., Writing: G.S.

\section{References}

1. World Health Organisation. Falls. http://www.who.int/ violence_injury_prevention/other_injury/falls/en/

2. Stewart RB, Moore MT, May FE, Marks RG, Hale WE. Nocturia: a risk factor for falls in the elderly. J Am Geriatr Soc 1992;40:1217-1220.

3. Kim SY, Bang W, Kim MS, Park B, Kim JH, Choi HG. Nocturia is associated with slipping and falling. PloS One 2017;12:e0169690.

4. Tunçay Uz, Özdinçler R, Erdinçler D. The Effect Of Rısk Factors For Falls On Actıvitıes Of Daıly Livıng And Quality Of Life In Gerıatrıc Patıents. Geriatr Gerontol Int 2017; 17 Suppl 1:36-43.

5. Olıver D, Daly F, Martin FC, Marıon E, Mcmurdo T. Risk Factors and Risk Assessment Tools for Falls In Hospital In-Patients: A Systematic Review. Age Ageing 2004;33:122-130.

6. Jayadevappa R, Chhatre S, Newman DK, Schwartz JS, Wein AJ. Association between overactive bladder treatment and falls among older adults. Neurourol Urodyn 2018;37:2688-2694.

7. Tan MP, Abdul Razack AH. Newer drugs to treat prostate symptoms are associated with increased risk of falls. Evid Based Nurs 2017;20:14.

8. Kim KS, Nam JW, Choi BY, Moon HS. The association of lower urinary tract symptoms with incidental falls and fear of falling in later life: The Community Health Survey. Neurourol Urodyn 2018;37:775-84.

9. Zhang X, Sun M, Liu S, et al. Risk factors for falls in older patients with cancer. BMJ Support Palliat Care 2018;8:34-37.

10. Seo GH, Shim SR, Lee HW, et al. Risk for Hip Fracture due to Alpha Blocker Treatment in Korean Women: National Health Insurance Database Study. Low Urin Tract Symptoms 2018;10:175-180.

11. Chen Y, Zhu LL, Zhou Q. Effects of drug pharmacokinetic/ pharmacodynamic properties, characteristics of medication use, and relevant pharmacological interventions on fall risk in elderly patients. Ther Clin Risk Manag 2014;10:437-448.

12. T.C. Sağlık Bakanlığı Sağlık Hizmetleri Genel Müdürlüğü, Sağlıkta Kalite ve Akreditasyon Daire Başkanlığı. http://www.kalite.saglik.gov. tr/index.php?lang=tr\&page $=267$.
13. Morse JM. Preventing Patient Falls: Second Edition. Newyork, Springer Publishing Company, 2008.

14. Karagiannis A, Skolarikos A, Alexandrescu E, et al. Epidemiologic study of urolithiasis in seven countries of South-Eastern Europe: S.E.G.U.R. 1 study. Arch Ital Urol Androl 2017;89:173-177.

15. Akinci M, Esen T, Tellaloğlu S. Urinary stone disease in Turkey: an updated epidemiological study. Eur Urol 1991;20:200-203.

16. Cumberbatch MGK, Foerster B, Catto JWF, et al. Repeat Transurethral Resection in Non-muscle-invasive Bladder Cancer: A Systematic Review. Eur Urol 2018;73:925-933.

17. Wildes TM, Maggiore RJ, Tew WP, et al; Cancer and Aging Research Group. Factors associated with falls in older adults with cancer: a validated model from the Cancer and Aging Research Group. Support Care Cancer 2018;26:3563-3570.

18. Winters-Stone KM, Moe E, Graff JN, et al. Falls and Frailty in Prostate Cancer Survivors: Current, Past, and Never Users of Androgen Deprivation Therapy. J Am Geriatr Soc 2017;65:1414-1419.

19. Wildes TM, Dua P, Fowler SA, et al. Systematic review of falls in older adults with cancer. J Geriatr Oncol 2015;6:70-83.

20. Sattar S, Alibhai SM, Spoelstra SL, Fazelzad R, Puts MT. Falls in older adults with cancer: a systematic review of prevalence, injurious falls, and impact on cancer treatment. Support Care Cancer 2016;24:4459-4469.

21. Demir MV, Taycı I, Yıldız H, Demir TÖ. Dahiliye Yoğun Bakım Hastalarının Düşme Riski Açısından Değerlendirilmesi. J Hum Rhythm 2016;2:122-125.

22. Çinarli T, Koç Z. Fear and Risk of Falling, Activities of Daily Living, and Quality of Life: Assessment When Older Adults Receive Emergency Department Care. Nurs Res 2017;66:330-335.

23. Oliver D, Daly F, Martin FC. Risk factors and risk assessment tools for falls in hospital inpatients. A systematic review. Age Ageing 2004;33:122-130.

24. McErlean DR, Hughes JA. Who falls in an adult emergency department and why-A retrospective review? Australas Emerg Nurs I 2017;20:12-16.

25. Urbanetto JS, Pasa TS, Bittencout HR, Franz F, Rosa VP, Magnago TS. Analysis of risk prediction capability and validity of Morse Fall Scale Brazilian version. Rev Gaucha Enferm 2017;37:e62200.

26. Baek S, Piao J, Jin Y, Lee SM. Validity of the Morse Fall Scale implemented in an electronic medical record system. J Clin Nurs 2014;23:2434-2440. 